\title{
PENGGUNAAN APLIKASI ZOOM DALAM PEMBELAJARAN DARING MAHASISWA PENDIDIKAN JASMANI STKIP PGRI JOMBANG
}

\author{
Arnaz Anggoro Saputro ${ }^{1)}$ \\ ${ }^{1}$ S1 Pendidikan Jasmani, STKIP PGRI Jombang \\ Email: arnazsaputro@gmail.com
}

\begin{tabular}{l}
\hline Artikel Info \\
\hline \\
Koresponden penulis: \\
Arnaz Anggoro Saputro \\
Email \\
arnazsaputro@gmail.com
\end{tabular}

Diterima 1 Oktober 2021

Direview 18 Januari 2022

Disetujui 29 Januari 2022

Dipublikasi 31 Januari 2022

Kata Kunci:

Pembelajaran Daring, Penggunaan, Aplikasi Zoom.

Keywords:

Online Learning, Zoom

\begin{abstract}
Abstrak
Dalam masa pandemi ini membuat kita melakukan segala kegiatan, seperti bekerja, sekolah, kuliah dan semua kegiatan yang biasanya dilakukan normal dan bisa dilaksanakan langsung namun ternyata semua tidak bisa dilaksanakan secara langsung, dalam hal ini khususnya pelaksanaan proses pembelajaran menjadi terkendala. Oleh karena itu dalam memanfaatkan teknologi maka dilaksanakan kegiatan pembelajaran dalam jaringan. Dan merupakan salah satu solusi yang dibutuhkan oleh tenaga pendidik dan mahasiswa di masa pandemi yang terjadi di awal tahun 2020. Perkembangan teknologi yang paling nyata pada saat ini adalah perkembangan internet. walaupun dalam masa pandemi kegiatan pembelajaran masih bisa dilaksanakan walaupun tidak secara langsung, tujuan penelitian ini dilatar belakangi untuk mengetahui penggunaan aplikasi Zoom dalam pembelajaran daring mahasiswa pendidikan jasmani STKIP PGRI Jombang. Metode yang di gunakan yaitu dengan pendekatan kualitatif dengan metode deskriptif. Teknik pengumpulan data melalui observasi dan wawancara.
\end{abstract}

\begin{abstract}
During this pandemic period, we are forced to carry out all activities, such as work, school, lectures and all activities that are usually carried out normally and can be carried out directly, but apparently all cannot be carried out directly, in this case, especially the implementation of the learning process is hampered. Therefore, in utilizing technology, learning activities are carried out in the network. And is one of the solutions needed by educators and students during the pandemic that occurred in early 2020. The most obvious technological development at this time is the development of the internet. Although during the pandemic, learning activities can still be carried out, although not directly, the purpose of this research is to find out the use of the Zoom application in online learning for physical education students at STKIP PGRI Jombang. The method used is a qualitative approach with a descriptive method. Data collection techniques through observation and interviews.
\end{abstract}




\section{PENDAhuluan}

Pemanfaatan Internet Untuk efektivitas aplikasi zoom terhadap kualitas pembelajaran jarak jauh mahasiswa Pendidikan Masyarakat. Dapat memperkaya ilmu pendidikan. Pendidikan merupakan hal yang tidak bisa dihindari oleh setiap manusia. Pendidikan merupakan upaya pengembangan manusia maupun masyarakat untuk menuju kehidupan yang lebih baik, karena pendidikan sangat berperan penting bagi kemajuan dan kehidupan umat manusia. (Sondari, Amri, \& Nurhayati, 2018) Namun dengan adanya pendidikan pemanfaatan internet dapat digunakan dengan sebaik mungkin. Pada dasarnya pendidikan dapat berperan menyelesaikan masalah yang terjadi, khususnya pada pemanfaatan internet. Internet merupakan suatu jaringan komputer yang terdiri dari berbagai perangkat komputer, menghubungkan suatu protocol tertentu untuk pertukaran informasi antar komputer. Dengan TCP/IP (Transmission Control Protocol/Internet Protocol) dapat melakukan pertukaran informasi melalui protocol yang sama di dalam komputer yang terhubung ke internet. (Shahab, 2000) Di seluruh dunia menggunakan internet untuk mengakses dan layanan telekomunikasi dari sumberdaya informasi. (Setiyani, 2010). Meningkatkan nilai manfaat dari internet dikarenakan pesatnya perkembangan kuantitas pengguna internet. Pemanfaatan
Internet sebagai sumber informasi belum mendukung pendidikan secara maksimal. (Setiyani, 2010).

Perkembangan teknologi yang paling nyata saat ini adalah perkembangan internet. Internet Merupakan tempat untuk mencari informasi dan memanipulasi informasi yang sudah ada, serta maupun menciptakan dan menyebarkan informasi baru. Akibatnya seseorang dapat mengakses informasi apapun, baik yang sangat berguna maupun tidak. apalagi dalam situasi pandemi seperti saat ini yang banyak mengharuskan orang belajar dari rumah secara online ataupun bekerja dari rumah work from home, pada saat ini dengan adanya pandemic Covid 19 yang melanda belahan dunia termasuk Indonesia menjadikan banyaknya pekerjaan yang dilakukan oleh manusia dengan mengunakan ragam aplikasi yang menunjang pekerjaannya dan pembelajaran bagi pendidik, siswa dan mahasiswa. Dalam situasi pandemic aplikasi zoom sebagai yang guna nya untuk video conferencing, Ini banyak digunakan berbagai kalangan seperti pembelajaran jarak jauh yang dilakukan dosen dengan mahasiswa, karena efektivias dan kualitas aplikasi zoom mempunyai audio dan video dapat tetap terjaga meskipun koneksi internet tidak stabil. Pada zaman yang semakin canggih sehingga banyak media pembelajaran yang dapat digunakan sangat banyak global dan visual. Dari hasil penelitian menjelaskan bahwa media pembelajaran menggunakan video 
sangat membantu dalam proses pembelajaran baik formal maupun non formal (Dennisa, 2016: 85).

Sejak masa pandemi covid 19 yang terjadi di Indonesia awal tahun 2020, peneliti tertarik untuk meneliti tentang aplikasi Zoom yang digunakan sebagai alternatif media pembelajaran dari pertemuan tatap muka atau langsung kemudian diganti dengan video conference yang dapat diakses oleh mahasiswa dan dosen untuk tetap menjaga kualitas dan efektivitas proses pembelajaran tetap berjalan meskipun ditengah pandemic seperti sekarang yang tengah melanda negeri ini. Berangkat dari pandemic saat ini banyak apliksi atau media pembelajaran bertebaran, namun saat di masa pandemic ini banyak yang lebih tertarik dengan menggunakan aplikasi Zoom karena lebih mudah dalam penggunaanya, keamanannya dan efektif dalam melakukan diskusi atau pembahasan materi dengan komunikasi yang didukung dengan fitur-fitur yang terdapat di aplikasi Zoom seperti fitur pesan grup, dan jika ada kendala secara audio dapat dibantu juga dengan fitur lainnya seperti fitur chat yang tersedia di aplikasi Zoom. Ahli Teknologi Informasi (IT), (Abimanyu Wachjoewidajat, 2020) memandang aplikasi Zoom yang saat ini popular digunakan selama masa pandemi, Aplikasi Zoom Banyak digunakan sebagai perangkat penunjang untuk melakukan pekerjaan atau pembelajaran dari jarak jauh atau dari rumah.

\section{METODE PENELITIAN}

Metode penelitian yang digunakan pada penelitian ini adalah kualitatif deskriptif. (Moleong, 2012:6) mengatakan bahwa penelitian kualitatif adalah penelitian yang bermaksud untuk memahami fenomena tentang apa yang dialami oleh subjek penelitian, misalnya perilaku, persepsi, motivasi dan tindakan secara holistik dan dengan cara deskripsi dalam bentuk kata-kata dan bahasa, pada suatu konteks khusus yang alamiah dan dengan memanfaatkan metode alamiah.

Metode penelitian kualitatif dinamakan sebagai metode baru, karena popularitasnya belum lama, dinamakan metode post positivisme. Metode ini disebut juga sebagai metode artistik, karena proses penelitian bersifat seni dan disebut sebagai metode interpretive karena data hasil penelitian lebih berkenaan dengan interprestasi terhadap data yang ditemukan dilapangan. (Sugiyono, 2017). peneliti adalah instrument kunci, oleh karena itu peneliti harus memiliki bekal teori dan wawasan yang luas jadi bisa bertanya, menganalisis dan mengkonstruksi obyek yang diteliti menjadi lebih jelas. yang bertujuan untuk melihat tingkat pemanfaatan internet terhadap Implementasi pembelajaran jarak jauh melalui aplikasi zoom untuk mahasiswa Pendidikan Jasmani STKIP PGRI Jombang . Populasi merupakaan penggeneralisasian berupa subjek/ objek yang di teliti untuk dipelajari dan kemudian diambil 
kesimpulannya dan yang menjadi populasi penelitian ini mahasiswa Pendidikan Jasmani STKIP PGRI Jombang angkatan 2017, 2018 dan 2019. Sampel adalah sebagian populasi yang dijadikan sebagai objek/ subjek penelitian, setiap angkatan diambil 5 orang mahasiswa sebagai sample peneliti. Analisis data dalam penelitian ini ditempuh dengan prosedur: Reduksi Data, Data Display, Kesimpulan dan Verifikasi.

\section{HASIL DAN PEMBAHASAN}

\section{Hasil}

Berdasarkan penelitian yang di lakukan, ditemukan hasil sebagai Pembelajaran Daring dimana dari hasil wawancara dan observasi terhadap mahasiswa Pendidikan Jasmani STKIP PGRI Jombang terutama responden AZ, DA, ED, IX, ZY menyebutkan bahwa pembelajaran yang dilaksanakan secara daring dapat membantu pelaksanaan perkuliahan bagi mahasiswa Pendidikan Jasmani. Hal ini karena pembelajaran secara daring tidak lagi terikat dengan jarak dan waktu. Dengan memanfaatkan aplikasi zoom meeting proses perkuliahan tatap muka dapat diganti dengan sistem online. Pembelajaran daring yang kita lakukan yaitu dengan memanfaatkan internet sebetulnya pembelajaran daring ini sudah dicanangkan jauh-jauh hari sebelum adanya pandemi, tapi masa pandemi ini memaksa dunia pendidikan untuk berevolusi, jadi pembelajaran daring ini sebagai solusi bagi mahasiswa yang memang kondisinya tidak memungkinkan untuk datang ke kampus, dan ini menjadi gambaran bahwa pendidikan di STKIP PGRI Jombang bisa menjangkau mahasiswa di berbagai lokasi, walaupun pembelajaran daring dengan menggunakan internet masih memiliki kelebihan dan kelemahan, tetapi menjadi solusi implementasi pendidikan pada saat ini.

Dalam pembelajaran jarak jauh setiap mahasiswa pasti akan mengalami segala kondisi yang terjadi dalam pelaksanaannya namun kita mahasiswa dan dosen sepakat agar pembelajaran dan perkuliahan tetap berjalan sesuai dengan jadwal dan waktu perkuliahan dengan Implementasi pembelajaran daring berdasarkan pada hasil wawancara dan observasi diperoleh bahwa pembelajaran daring memiliki efektifitas yang baik. Walaupun masih memiliki beberapa kendala, terkait adaptasi mahasiswa dan dosen dalam pengunaan aplikasi daring. Aplikasi zoom meeting memiliki keunggulan dalam memfasilitasi pembelajaran terutama dengan video streaming sehingga mahasiswa mampu menerima tampilan visual secara baik dan menghindari miskomunikasi dalam proses pembelajaran.

\section{Pembahasan}

Dari hasil penelitian diatas seperti halnya penelitian yang pernah dilakukan sebelumnya bahwa pembelajaran jarak jauh pada saat ini efektif untuk dilaksanakan walaupun didalamnya pasti selalu ada kekurangan dan kelebihan namun pada dasarnya apapun alasannya pembelajaran harus bisa tetap 
http://jurnal.unipasby.ac.id/index.php/stand/about/submissions jurnal.stand@unipasby.ac.id

dilaksanakan walaupun dalam situasi pandemi yang terjadi saat ini, dan bisa dilaksanakan dengan pembelajaran jarak jauh. Dengan kemampuan teknologi yang dimiliki "Komputer" menjadi sarana yang efektif dan efesien untuk dijadikan sebagai modalitas dalam pembelajaran. Inilah yang menjadikan teknologi komputer memberi banyak ragam dalam pembelajaran.

Pembelajaran jarak jauh merupakan salah satu bagian konsep Pendidikan luar sekolah yang hingga saat ini masih relevan dengan implementasi Pendidikan Masyarakat. Hal ini senada dengan pendapat dari Ansori \& Mulyono (2012) tentang pembelajaran jarak jauh, yang berhubungan dengan literasi informasi di tengah masyarakat. Konsep ini sesuai dengan hasil temuan peneliti yang dilakukan, bahwa mahasiswa masih membutuhkan pembelajaran tatap muka, terutama dengan menggunakan Video Conference.

Kemudian berkaitan dengan efektifitas pembelajaran secara daring ditemukan bahwa proses pembelajaran melalui aplikasi Zoom Meeting memiliki keunggulan seperti kemudahan akses dan efesiensi waktu. Namun demikian kendala jaringan yang dihadapi oleh dosen maupun mahasiswa menjadi tantangan tersendiri terutama berhubungan dengan kelancaran proses pembelajaran yang ada di prodi penmas. Hal ini senada dengan pendapat dari Widiastuti (2009) yang menjelaskan bahwa proses pembelajaran membutuhkan media pendukung yang memadai untuk mencapai tujuan pembelajaran.

\section{KESIMPULAN}

Berdasarkan pemaparan dan hasil penelitian yang telah penulis uraikan dapat di ambil kesimpulan bahwa Efektivitas pembelajaran jarak jauh dengan aplikasi zoom untuk mahasiswa pendidikan masyarakat IKIP Siliwangi sangatlah efektif dan menjadi alternatif media pembelajaran online di tengah pandemi covid-19. dan dapat memaksimalkan pembelajaran yang diterima oleh mahasiswa selain didalam kelas namun dapat dilakukan diluar kelas melalui aplikasi zoom yang mampu di akses oleh mahasiswa dan dosen. Melalui aplikasi zoom dosen dan mahasiswa dapat melakukan video konferensi yang dijadikan sarana berkomunikasi dalam pembelajaran jarak jauh secara online. Melalui aplikasi zoom lebih terjaga keamanan rekaman yang dilakukan pada saat meeting berlangsung, suasana pembelajaran menjadi lebih interaktif dan diminati oleh mahasiswa karena media pemeblajaran online yang digunakan sangat inovatif dan efektif sesuai dengan perkembangan teknologi dan zaman. Keberlangsungan metode pembelajaran video konferensi melalui aplikasi zoom bergantung pada jaringan internet sehingga mahasiswa dan dosen harus menggunakan akses internet agar dapat menggunakan aplikasi zoom. 


\section{REFERENSI}

Dennisa, A. d. (2016). Pembelajaran Berbasis Video Untuk Anak Generasi Z. Prosiding Inovasi Pendidikan di Era Big Data Aspek Psikologinya (pp. 8592). Malang: Pasca Sarjana Universitas Malang.

Firda, A., \& dkk. (2016). Pembelajaran Berbasis Online Social Networking (OSN) dalam Meningkatkan Kemampuan Menulis Argumentative Essay Mahasiswa. ProsidingInovasi Pendidikan di Era Big Data dan Aspek Psikologinya.ISSN: 2458-5407 (pp. 145-150). Malang: Pasca Sarjana Universitas Negeri Malang.

Irianto, R. P. (2020, September 2). https://m.mediaindonesia.com/read/det ail/308048-ahli-it- zoom-bukanaplikasi-berbahaya. Retrieved from www.mediaindonesia.com:

http://www.mediaindonesia.com

Moleong, L. J. (2012 :6). Metodologi Penelitian Kualitatif. Bandung: PT. RemajaRosdakarya.

Setiyani, R. (2010). Pemanfaatan Internet Sebagai Sumber Belajar. Jurnal Pendidikan Ekonomi Dinamika Pendidikan, 119-133.

Shahab, A. (2000). Internet Bagi Profesi Guru. Jakarta: EGC.

Sondari, Y., Amri, D., \& Nurhayati, S. (2018). Penerapan Pendidikan Inklusif Pada Program Kesetaraan di PKBM Srikandi. Jurnal Com Edu 1 (13)., 7093.

Sugiyono. (2017). Metode Penelitian Kuantitatif, Kualitatif, dan R\&D. Bandung: Alfabeta.

Uci, R. (2017). Manfaat Panduan Belajar yang Diintegrasikan Dengan Tutorial Online (PBTO) Dalam Meningkatkan Kemandirian Belajar dan Keberhasilan Studi Mahasiwa Jarak Jauh (PJJ). Skripsi tidak diterbitkan. Bandung: UPI.Repository.upi.edu perpustakaan.upi.edu. 